\title{
NEOLIBERALISMO ESCOLAR: A EDUCAÇÃO DE JOVENS NA ATUALIDADE E SEUS EFEITOS SUBJETIVOS
}

\author{
School Neoliberalism: The Education of Young People Today and Its Subjective Effects
}

Neoliberalismo Escolar: La Educación de Jóvenes en la Actualidad y sus Efectos Subjetivos

Néolibéralisme Scolaire : L'Éducation des Jeunes d'Aujourd'hui et ses Effets Subjectifs

\section{Lorenna Pinheiro Rocha 9}

Professora do curso de Psicologia da Universidade de Fortaleza. Doutoranda no Programa de Pós-Graduação em Psicologia da Universidade de Fortaleza. Mestra em Psicologia Social e Institucional pela Universidade Federal do Rio Grande do Sul.

\section{Maria Celina Peixoto Lima 9}

Professora titular do Programa de Pós-Graduação em Psicologia da Universidade de Fortaleza. Doutora em Psicologia pela Universidade Paris XIII (França).

\section{Clara Virgínia de Queiroz Pinheiro 9}

Professora titular do Programa de Pós-Graduação em Psicologia da Universidade de Fortaleza. Doutora em Saúde Coletiva pela Universidade Estadual do Rio de Janeiro.

\section{Resumo}

$\mathrm{Na}$ atualidade, presenciamos um nítido esfacelamento dos fundamentos e finalidades da educação, o que vem deixando incerta sua atual função social. Se, um dia, seu papel se centrou numa formação intelectual e cidadã, a partir da transmissão dos valores da cultura e dos referenciais simbólicos da sociedade, tal propósito vem sofrendo profundas transformações com o advento do neoliberalismo escolar, que consiste na migração dos valores econômicos para o campo educacional. Nesse contexto, a escola passa a ser convocada a responder a interesses econômicos, o que se torna evidente ao analisarmos, sobretudo, as propostas pedagógicas voltadas à juventude. Diante desse cenário, o presente trabalho busca discutir as consequências da entrada dos valores econômicos na educação de jovens, atentando para os seus efeitos no sujeito/aluno. Sugerimos, aqui, duas modalidades distintas de sintomas escolares que se presentificam na relação com o saber: as inibições intelectuais e a melancolização. Tais sintomas dão testemunho de um preocupante declínio do sentido do conhecimento, que representa uma das principais mazelas com que a escola precisa lidar na atualidade. Partindo da concepção psicanalítica de que o sentido só se constrói na referência a outro, tal problemática não se resolveria com tentativas de conferir sentidos individuais ao conhecimento, como temos observado nas práticas educativas contemporâneas. Progressivamente, o aspecto coletivizante do conhecimento vem perdendo seu lugar em detrimento de uma compreensão mais individualizada, segundo a qual a educação funciona como instrumento de "modelagem" de competências exigidas pelo mercado de trabalho. Assim, concluímos que a necessidade de se resgatar o caráter coletivizante do conhecimento é urgente; há que se levar em consideração as condições de possibilidade de uma real transmissão no contexto escolar, pois o triunfo de um modelo educacional que se propõe a responder a demandas de eficácia e de inovação encontra seus limites na própria natureza do ato pedagógico.

Palavras-chave: educação; juventude; psicanálise; neoliberalismo escolar.

\section{Abstract}

Currently, we have witnessed a clear breakdown of the fundamentals and purposes of education, which has left its current social function uncertain. If one day, its role was centered on an intellectual and citizen formation, from the transmission of the values of culture and 
the symbolic references of society, this purpose has undergone profound changes with the advent of school neoliberalism, which consists in the migration of economic values for the educational field. In this context, the school is called upon to respond to economic interests, which becomes evident when we analyze, above all, the pedagogical proposals aimed at youth. Given this scenario, this paper seeks to discuss the consequences of the entry of economic values in the education of young people, paying attention to its effects on the subject/student. Here, we suggest two different types of school symptoms that are present in the relationship with knowledge: intellectual inhibitions and melancholy. Such symptoms testify to a worrying decline in the sense of knowledge, which represents one of the main problems that the school needs to deal with today. Starting from the psychoanalytic conception that the meaning is an only built-in reference to another, this problem would not be solved with attempts to give individual meanings to knowledge, as we have observed in contemporary educational practices. Progressively, the collectivizing aspect of knowledge has been losing its place at the expense of a more individualized understanding, according to which education works as an instrument for the "modeling" of skills required by the labor market. Thus, we conclude that the need to rescue the collectivizing character of knowledge is urgent; it is necessary to take into account the conditions of possibility of a real transmission in the school context since the triumph of an educational model that aims to respond to demands for efficiency and innovation finds its limits in the very nature of the pedagogical act.

Keywords: education; youth; psychoanalysis; school neoliberalism.

\section{Resumen}

En la actualidad, presenciamos un nítido destrozar de las bases y finalidades de la educación, lo que viene dejando dudosa su actual función social. Si, algún día, su función se fijó en una formación intelectual y ciudadana, a partir de la transmisión de los valores de la cultura y de los referenciales simbólicos de la sociedad, tal propósito viene sufriendo transformaciones profundas con la llegada del neoliberalismo escolar, que consiste en la migración de los valores económicos para el campo educacional. En este contexto, la escuela pasa a ser convocada a contestar a intereses económicos, lo que queda claro al analizar, sobretodo, las propuestas pedagógicas dirigidas a la juventud. Ante este escenario, el presente trabajo busca discutir las consecuencias de la entrada de los valores económicos en la educación de jóvenes, con atención para sus efectos en el sujeto/alumno. Sugerimos, aquí, dos modalidades distintas de síntomas escolares que se ponen presentes en la relación con el saber: las inhibiciones intelectuales y la melancolización. Estos síntomas son testigos de un preocupante declive del sentido del conocimiento, que representa una de las principales desgracias con que la escuela necesita enfrentar en la actualidad. Partiendo de la concepción psicoanalitica de que el sentido solo se construye en la referencia a otro, esta problemática no sería solucionada con intentos de conceder sentidos individuales al conocimiento, como observamos en las prácticas educativas contemporáneas. Progresivamente, el aspecto colectivo del conocimiento está perdiendo su sitio debido a una comprensión más individualizada, donde la educación funciona como instrumento de "modelado" de competencias exigidas por el mercado de trabajo. Así, concluimos que es urgente la necesidad de rescatar el carácter colectivo del conocimiento; se debe llevar en cuenta las condiciones de posibilidad de una real transmisión en el contexto escolar, porque el logro de un modelo educacional que se propone a responder la demanda de eficacia y de innovación encuentra límites en la propia naturaleza del acto pedagógico.

Palabras clave: educación; juventud; psicoanálisis; neoliberalismo escolar.

\section{Résumé}

Aujourd'hui, nous sommes témoin d'une corruption claire des fondements et des objectifs de l'éducation, ce qui laisse sa fonction sociale incertaine pour l'actualité. Si, un jour, son rôle était centré sur une formation intellectuelle et citoyenne, à partir de la transmission des valeurs, de la culture et des références symboliques de la société, cette finalité a subi de profonds changements avec l'avènement du «néolibéralisme scolaire», qui consiste en la migration des valeurs économiques pour le domaine éducatif. Dans ce contexte, l'école est appelée à répondre à des intérêts économiques, ce qui devient évident lorsque l'on analyse, avant tout, les propositions pédagogiques destinées aux jeunes. Devant ce scénario, le présent travail vise à discuter des conséquences de l'entrée des valeurs économiques dans l'éducation des jeunes, en examinant leurs effets sur le sujet/étudiant. Nous suggérons, donc, deux modalités différentes de symptômes scolaires présents dans le rapport à la connaissance : inhibitions intellectuelles et mélancolie. De tels symptômes témoignent un déclin inquiétant du sens de la connaissance, ce qui représente l'un des principaux problèmes que l'école doit affronter aujourd'hui. Partant de la conception psychanalytique que le sens ne se construit qu'en référence à un autre, ce problème ne se résoudrait pas par des tentatives de donner des significations individuelles à la connaissance, comme nous avons observé dans les pratiques éducatives contemporaines. Progressivement, l'aspect collectif de la connaissance a perdu sa place au détriment d'une compréhension plus individualisée, selon laquelle l'éducation fonctionne comme un instrument de "modélisation » des compétences requises par le marché du travail. De cette façon, nous concluons que la nécessité de sauver le caractère collectif de la connaissance est urgente ; il faut prendre en compte les 
conditions de possibilité d'une transmission réelle dans le contexte scolaire, puisque le triomphe d'un modèle éducatif qui propose de répondre à des demandes d'efficacité et d'innovation trouve ses limites dans la nature même de l'acte pédagogique.

Mots-clés : éducation ; jeunesse ; psychanalyse ; néolibéralisme scolaire.

Embora a educação seja comumente entendida como fator decisivo de progresso de uma nação, o que a torna um dos principais alvos de investimentos públicos, sobretudo nos países economicamente mais desenvolvidos, presenciamos, na atualidade, um nítido esfacelamento dos seus fundamentos e finalidades, deixando incertos os contornos de sua real função social.

Se retornarmos à Paideia grega, perceberemos, claramente, o atravessamento de um discurso filosófico e político no campo da educação, por meio do qual lhe era atribuída uma função civilizatória na formação humana. Educava-se para a vida na pólis, fundamentando-se na cientificidade, na virtude e na política, com vistas a se atingir a excelência (Jaeger, 2003).

Tal compreensão deu origem ao modelo educacional que presenciávamos há não muito tempo atrás, que consistia numa formação intelectual e cidadã por meio da transmissão dos valores da cultura e dos referenciais simbólicos da sociedade (Laval, 2019), promovendo, pela via do saber, a emancipação e a autonomia (Adorno, 2003). Esse propósito, no entanto, vem sofrendo profundas transformações com a entrada da lógica neoliberal no contexto escolar.

Capturada pela lógica capitalista, a escola passa a ser convocada a responder a interesses de cunho econômico. Educase numa perspectiva de "instrumentalização do indivíduo", de modo a agregar valor ao capital humano que ele tem a oferecer ao mercado. Assim, o papel que a educação desempenha na atualidade acaba submetido aos imperativos do sucesso profissional e da eficiência, lugar bem diferente, portanto, daquele que ocupava na formação do homem grego.

Nesse contexto, as condutas dos alunos - e, aqui, chamamos a atenção, principalmente, para o público jovem, que se encontra em vias de conclusão da educação básica e, portanto, de ingresso no mercado de trabalho - tornam-se objeto de práticas educativas que visam não mais a excelência, mas ao desempenho individual. Nesse sentido, a perspectiva coletivizante do conhecimento, ou seja, a possibilidade de uma formação humana mais comprometida com os problemas gerais da sociedade, acaba por perder sua razão de ser (Voltolini, 2012).

Trazendo para a realidade brasileira e dando destaque à situação específica do ensino médio, temos observado uma forte tendência à tecnificação do campo educacional, com vistas a se alcançar as metas traçadas para uma educação do século XXI com a máxima eficácia. Os modelos educativos tradicionais, portanto, tornam-se obsoletos e, em nome de sua modernização, novas metodologias são criadas, dispositivos tecnológicos são incorporados às salas de aula e os próprios conteúdos curriculares modificam-se para dar conta das demandas que chegam aos jovens alunos, geralmente relacionadas ao mundo do trabalho. Deles, exigese que finalizem seus percursos escolares com certo conjunto de habilidades e competências bem desenvolvido, de modo a que possam, enfim, dar início a uma vida produtiva de forma satisfatória. Proatividade, amabilidade, extroversão, abertura a novas experiências, capacidade de resolução de conflitos e de trabalho em equipe, conscienciosidade, estabilidade emocional (Goldberg, 1990), entre outras, costumam ser apontadas como características que definem o perfil ideal do estudante/profissional do século XXI (Fadel, Biliak, \& Trilling, 2016).

No entanto, ao adentrarmos o contexto escolar propriamente dito, é com outra conjuntura que, não raro, nos deparamos. Desinteresse, baixo rendimento, baixa assiduidade, condutas associais por parte dos alunos e altos índices de evasão escolar - que quintuplicam no ensino médio (11,7\%) quando comparados aos anos iniciais do ensino fundamental (2,3\%) (Ministério da Educação [MEC], 2017) - são apenas alguns dos exemplos que ilustram esse preocupante cenário. Em situações ainda mais graves, temos a adesão de um número cada vez maior de jovens às práticas de cutting (automutilação), à depressão, ao consumo abusivo de álcool e outras drogas, e às tentativas de suicídio, que crescem a cada ano no Brasil.

Numa leitura psicanalítica, tomando como base esse breve panorama, podemos sugerir duas modalidades distintas de sintomas escolares: os referidos às inibições intelectuais, que aparecem sob o formato de um "fracasso escolar", podendo chegar a impossibilitar que o aluno consiga dar continuidade ao seu processo de escolarização, e aqueles que fazem referência a certa melancolização ${ }^{1}$, que se dá a ver no desinteresse dos alunos pelos estudos, bem como nas tentativas de suicídio e nas automutilações. Assim, podemos concluir que, mais do que a educação infantil, parece ser o cenário do ensino médio que denuncia uma crise no campo educacional, questão com a qual Hannah Arendt (2007) já se encontrava envolvida desde a década de 1950.

À época, a autora apontava algumas das possíveis razões para tal crise. A primeira está relacionada ao abandono a que as crianças são levadas em seus processos educativos como consequência direta da concepção de que devem, o quanto antes, conquistar sua autonomia. A segunda diz respeito ao surgimento da pedagogia como uma ciência do ensino que

1 Aqui, cabe esclarecer, não estamos tomando a melancolização como índice de uma estrutura clínica na qual se situariam os jovens que apresentam um quadro semelhante ao descrito por Freud como melancólico. 
independe daquilo que é ensinado, deslocando o professor, portanto, do lugar de autoridade em certo conhecimento ao lugar de facilitador da aprendizagem. Por fim, a terceira razão deriva do pressuposto pragmático de que "só é possível conhecer e compreender aquilo que nós mesmos fizemos" (Arendt, 2007, p. 232).

Como podemos concluir, essas razões se encaixam perfeitamente e potencializam-se. Se é preciso saber ensinar mais do que saber aquilo que se propõe a ensinar, e se é buscado que o aluno seja autônomo em seu processo educacional, que aprenda por si mesmo e que aprenda "fazendo", o professor perde a fonte legítima de sua autoridade (Lima \& Lima, 2011). Nesse sentido, a crise na educação teria como principais fatores desencadeadores o declínio do lugar do professor/mestre e a consequente adesão à ideia da supremacia das técnicas pedagógicas como garantia do sucesso da aprendizagem.

Neste trabalho, partindo de uma pesquisa teórico-bibliográfica, abordaremos a problemática da crise na educação que presenciamos na contemporaneidade, sobretudo no que se refere à educação de jovens, atentando para os impactos da entrada da lógica capitalista e neoliberal no contexto escolar. Para tanto, partiremos de algumas considerações acerca das especificidades da educação de jovens no Brasil, abordando a noção de "neoliberalismo escolar" proposta por Laval (2019) e o lugar que a teoria do capital humano assume nesse cenário. Em seguida, discutiremos, a partir da psicanálise, os efeitos no sujeito/aluno advindos desse tal cenário.

\section{A Educação de Jovens em Tempos de Neoliberalismo}

Numa leitura da Lei de Diretrizes e Bases da Educação Nacional (Lei no 9.394, 1996 e Lei no 12.796, 2013) em suas diversas reformulações, é possível identificar uma diferença discursiva no tratamento dado ao ensino médio quando o comparamos aos demais segmentos da educação básica. Ao passo em que as propostas direcionadas à educação infantil foram tomando contornos de uma via de inserção das crianças no plano da cultura, vinculando-se a práticas sociais e culturais num contexto mais amplo, a tônica da educação de jovens, por outro lado, recai sobre uma formação mais técnica, voltada, basicamente, para a inserção profissional ${ }^{2}$.

Assim, se a educação infantil, ao longo de sua história, foi moldando-se segundo uma via que envolve não apenas o aspecto formal da educação individual, mas, sobretudo, a interrelação social - no que concerne à relação da criança com os outros - e cultural - no que tange ao próprio meio no qual ela está inserida -, a educação dos jovens, em contrapartida, no lugar de avançar na ampliação desse quadro educacional integral, parece direcionar-se, cada vez mais, para a qualificação da mão de obra que vai alimentar o setor econômico.

A aliança entre o campo educacional e a lógica capitalista se torna ainda mais evidente ao analisarmos os principais documentos que orientam a construção dos currículos escolares voltados ao público jovem (Diretrizes curriculares nacionais da Educação Básica [MEC, 2013]; Diretrizes Curriculares Nacionais para a Educação Profíssional Técnica de Nível Médio [Resolução CNE/CEB N. 06/2012]; Referenciais Curriculares para a Educação Profissional Técnica Ministério da Educação [MEC, 2000]). Na redação dos textos, termos como "habilidades", "competências" e "empreendedorismo" ganham destaque, demonstrando um claro direcionamento das propostas pedagógicas para se alcançar "desempenho", "eficácia" e "eficiência" (MEC, 2000) - terminologias bastante caras, por exemplo, ao mundo empresarial.

Tentando responder a demandas de caráter essencialmente econômico, os currículos escolares acabam organizados de modo fragmentado e sem muitas conexões com a vida cotidiana ou com os interesses daqueles a quem se destinam. Os conteúdos programáticos são desarticulados de tal maneira que não há uma estrutura transversal que desperte a curiosidade dos alunos ou o seu interesse e busca pelo conhecimento (Bandeira \& Oliveira, 2012), já que servem a um propósito que, em geral, escapa à juventude.

Isso não é sem efeitos. Em meio à gama de possibilidades de acesso imediato e ilimitado à informação que presenciamos na contemporaneidade, os jovens alunos constantemente desnudam a falta de sentido naquilo que lhes tentam ensinar: "professor, por que eu preciso aprender isso?", "para que isso serve?", "vai cair na prova?", deflagrando, assim, a marca indelével da lógica utilitarista no cotidiano escolar. Alguns, ao concluírem que "não serve para nada aprender" - ou, pelo menos, que aprender o que as escolas tentam ensinar não tem serventia alguma para eles naquele momento - tomarão o caminho de satisfações mais imediatas decorrentes da adesão a objetos de consumo, enquanto outros entrarão num recolhimento quase autístico no campo do virtual, na internet e nos jogos eletrônicos (Lima \& Lima, 2011).

2 Cabe, aqui, o esclarecimento de que não nos opomos à ideia de que as escolas também se encarreguem da tarefa de oferecer a seus alunos algum espaço de preparação para o mercado de trabalho, principalmente quando levamos em consideração a realidade brasileira, que é marcada por preocupantes índices de desemprego. Nossa questão vai na direção de problematizar o quanto a educação de jovens, funcionando como qualificadora de mão de obra, vem sendo pensada e organizada numa relação quase que de servidão com o capitalismo, o que traz como consequência a perda da clareza do que a caracterizaria, ou seja, de qual seria, afinal de contas, a sua função na sociedade contemporânea. 
A esse respeito, Voltolini (2012) esclarece que a falta de sentido do conhecimento é uma das principais mazelas com que a escola precisa lidar na atualidade. Não se restringe ao âmbito discente, atingindo, também, os professores, que, cada vez mais, se veem convocados a realizar a difícil tarefa de defender, para além de seu próprio interesse particular, o valor dos conteúdos que ministram. Segundo o autor, esse declínio do sentido do conhecimento, no entanto, não se resolve com vãs tentativas de lhe conferir um sentido individual, justamente porque o sentido é algo que não pode ser encontrado fora da referência a outro, ou seja, fora de uma tradição. "Não há conhecimento cujo sentido não se assente no laço que o liga a uma turba discursiva na qual todos pegamos carona" (Voltolini, 2012, p. 113).

A questão, hoje, é que os mais experientes, dentre os quais podemos situar os professores, parecem tão angustiados com o futuro como o estão os mais jovens, de modo que duvidam de que ele possa ser promissor para si e para seus alunos. Sem a tradição das gerações anteriores para nortear em direção a algum horizonte de sentido sólido e discernível, o interesse dos alunos pelo aprender parece ir-se diluindo conforme vão avançando em sua escolarização para, aos poucos, transformar-se numa apatia quase incontornável quando chegam ao ensino médio (Oliveira, Lima, \& Colares, 2019).

Educar em tempos de império do capital não é, portanto, uma tarefa fácil. O conhecimento deixa de possuir valor de uso para adquirir valor de troca, funcionando como um produto a ser comercializado. A escola perde sua significação enquanto "templo do saber" e torna-se uma organização prestadora de serviços. O aluno, por sua vez, antes visto como um sujeito a quem a instituição escolar deveria conferir condição de cidadania, passa a ser definido em termos de aprendizados acumulados; aprendizados esses que só têm valor social se apresentarem alguma utilidade em termos de colocação profissional.

Nesse sentido, Laval (2019) aponta que a concepção dominante da educação tem duas dimensões: por um lado, ela é utilitarista no que diz respeito à ideia que confere ao saber, e, por outro, é liberal no modo de organização da escola. Se o conhecimento é tomado como uma ferramenta que deve servir a um indivíduo em sua tentativa de alcançar posições socioeconômicas mais vantajosas, a escola passa a ser vista como um instrumento de bemestar econômico, na medida em que parece existir apenas para preparar seus alunos para, num futuro próximo, serem exatamente o que as empresas necessitam. Mas se o conhecimento se torna um recurso privado que pode gerar rendas mais elevadas, a relação educacional facilmente passa a ser regida por uma lógica essencialmente comercial.

Foi tomando como base esse cenário que Laval (2019) cunhou o termo "neoliberalismo escolar" ao discutir a realidade atual do sistema educacional na França, que passa por um momento de derrocada do ensino público, movimento que, se na Europa ainda está sendo engendrado, no Brasil, já é fato consumado. A esse respeito, esclarece:

A escola neoliberal é a designação de certo modelo escolar que considera a educação um bem essencialmente privado, cujo valor é, acima de tudo, econômico. Não é a sociedade que garante o direito à cultura a seus membros; são os indivíduos que devem capitalizar recursos privados cujo rendimento futuro será garantido pela sociedade. Essa privatização é um fenômeno que atinge tanto o sentido do saber e as instituições que transmitem os valores e os conhecimentos quanto o próprio vínculo social. (Laval, 2019, p. 17)

Por "neoliberalismo escolar", portanto, devemos compreender a migração de determinados valores econômicos do campo da economia para o da educação, movimento pelo qual tais valores ganham forte poder normativo. Logo, quando a lógica neoliberal extrapola em demasiado os limites do campo econômico stricto sensu, a racionalidade do capital toma contornos de uma lei social geral. Assim, alunos vêm sendo transformados em microempreendedores, devendo capitalizar a si mesmos para tornarem-se atrativos e interessantes ao mercado de trabalho.

Esse fenômeno pode ser explicado pela teoria do capital humano proposta por Schultz (1973), que aponta que, quando um conjunto de habilidades se torna valor de troca, o "humano", por consequência, adquire valor de mercado e se apresenta como forma de capital por si próprio (López-Ruiz, 2007). O "trabalhador autônomo" é a nova referência do ideal pedagógico: o próprio indivíduo deve tentar incrementar seus recursos ao longo da vida com vistas a alcançar melhor renda e posição social.

A esse respeito, Acúrcio e Andrade (2005, p. 12) afirmam que,

em momentos históricos cuja organização social é marcada por problemas como o desemprego, a má distribuição de renda, a desigualdade de oportunidades e a violência, investir no empreendedorismo parece ser a melhor solução. (...) As instituições educacionais podem colaborar na solução dessas dificuldades socioeconômicas, preparando pessoas para empreender, gerar empregos, criar riquezas para o país.

Seguindo essa lógica, os alunos passam a funcionar como microempresas (Costa, 2009), consistindo, simultaneamente, em capital e renda. 
Decomposto do ponto de vista do trabalhador, em termos econômicos, o trabalho comporta um capital, isto é, uma aptidão, uma competência; como eles dizem: é uma máquina. Por outro lado, é uma renda, isto é, um salário ou, melhor ainda, um conjunto de salários; como eles dizem: um fluxo de salários. (Foucault, 2008, p. 308)

Assim sendo, a própria noção de "humano" modifica-se. O "homem" torna-se um indivíduo estranho, ainda malesboçado, possuidor de um corpo já não mais mecânicoorgânico, mas pósorgânico e tecnológico. Sua identidade, formas de pensar, agir e sentir já não são constituídas por uma normatividade médico-psicológica, mas, cada vez mais, são produzidos por uma normatividade econômico-empresarial (Costa, 2009). Exemplo disso são os quadros de honra expostos com as fotografias dos "melhores alunos" nas escolas, tal qual o fazem empresas e indústrias com o "funcionário do mês".

Essa nova concepção de educação, ao pautar-se nos imperativos da eficiência e do desempenho individual, acaba por torná-la um solo extremamente fértil para o enraizamento da competitividade característica do meio empresarial.

Como consequência, cenas de um cotidiano marcado por intensa hostilidade se multiplicam no contexto escolar. Enquanto, na infância, a escola se configura como um espaço de inserção no laço social, onde as crianças devem aprender a conviver com seus pares e a dividir seus brinquedos; na juventude, os colegas são transformados em adversários/concorrentes na corrida para se conquistar o primeiro lugar da turma ou, mais adiante, uma vaga nas universidades ou no mercado de trabalho.

$\mathrm{O}$ fato é que essa lógica do empreendedorismo traz efeitos importantes para a construção de uma nova discursividade nas searas educativas. Se "o empreendedor é alguém que aprende sozinho" (Dolabela, 1999, p. 24), a iniciativa individual e o processo de aprender a aprender (Delors, 1998) passam a ser valorizados em detrimento do trabalho em equipe e, até mesmo, do próprio ensino, fazendo que os professores percam a fonte legítima de sua autoridade, questão já discutida por Arendt (2007). O sistema educacional, assim, torna-se um apêndice da máquina econômica numa perspectiva que desloca a atenção do saber-fazer - que pressupunha a participação direta de outro num compartilhamento de experiências - para o puro fazer individualizado.

Duarte (2001) chama a atenção para o fato de que, nessa perspectiva, o professor se limitaria a exercer a função de guia, de mediador do processo de aprendizagem, deslocando-se da dimensão do ensino para a do treinamento (coaching) de competências (Perrenoud, 1999). Levando em consideração que a noção de competência faz referência a um conhecimento não desatrelado da ação, um saber que é, em seu cerne, prático, ela responde muito bem ao modelo educacional vigente, que considera mais desejável o conhecimento ao qual se chega sozinho.

O problema é que essa concepção traz consigo um sério risco de desintelectualização e desformalização dos processos de aprendizagem (Laval, 2019). Como, por exemplo, mobilizar a atividade intelectual dos jovens alunos se o próprio modelo educativo ao qual estão submetidos parece foracluir a possibilidade de uma real transmissão ${ }^{3}$ no contexto escolar? Além disso, muito se fala, no mundo corporativo, sobre colaboração, cooperação e espírito de equipe, mas como conciliar tais habilidades e competências com a iniciativa individual de que falávamos?

López-Ruiz (2007) observa que, nesse contexto, o vínculo entre o indivíduo e a empresa é melhor definido pelo ensemble individualism: "este tipo de configuração permite que cada indivíduo, cada capitalista em relação de dependência, gerencie seu próprio business dentro da corporação: 'seu projeto', para o qual, conforme as necessidades do momento, vai se associar com outras pessoas nos efêmeros teams” (p. 243).

Diante desse cenário, podemos supor que essa fria racionalidade traz, como efeito, fragilidade e fugacidade para as relações interpessoais. Assim, Costa (2009) afirma que:

por isso mesmo, essas mônadas investidoras também parecem cada vez menos capazes de se agenciarem entre si em torno da invenção de novos modos de vida, e de intervenção em favor de novos modos de existencialização e de sensibilidade, que não aqueles apregoados pelo mercado, de tão inseguras que estão (...), ou porque se rivalizam como concorrentes (...), ou ainda por estarem entorpecidas por processos e políticas de subjetivação que as serializam e homogeneízam, levando-as à passividade política e mesmo ao adoecimento psíquico. (p. 182)

Transpondo tal realidade para o contexto escolar, as consequências são nefastas. Se, na juventude, o encontro com o outro se configura como necessário à construção de novos suportes imaginários/simbólicos que sustentem os jovens para além da família (Rassial, 2002), a lógica empresarial contemporânea parece contribuir para que esse processo, não raro, falhe, deixando os jovens numa completa deriva diante das incertezas que cercam suas próprias existências.

3 Aqui, fazemos referência ao sentido freudiano de transmissão, que será abordado mais adiante. 


\section{Os Efeitos Subjetivos da Lógica Neoliberal no Campo da Educação}

Alguns dos trabalhos que, direta ou indiretamente, consideram as questões relacionadas às especificidades da educação de jovens tomam, como centro da discussão, a sua relação transferencial ao mestre, seus desdobramentos e impasses evidenciados pela contemporaneidade (Gutierra, 2002; Rassial, 2002).

Freud (1914/2006c, p. 249), em seu artigo Algumas reflexões sobre a psicologia do escolar, já alertava sobre o valor da personalidade do professor no despertar do amor juvenil pelas ciências: "Não sei o que mais nos absorveu e se tornou mais importante para nós: as ciências que nos eram apresentadas ou as personalidades de nossos professores". Assim, podemos inferir que, para Freud, o caminho do saber passaria, inevitavelmente, pelas pessoas dos professores.

Muito tempo já se passou desde a publicação do texto freudiano e o contexto social não é mais o mesmo. Autores mais recentes (Kupfer, 2000; Nóvoa, 1999; Pereira, 2013) salientam que, na contemporaneidade, observamos os efeitos de um enfraquecimento das referências simbólicas na escola, já que a autoridade do professor é constantemente questionada pela ideia de que vale mais aquilo que é aprendido sem intermédio de outro (Duarte, 2001). Como consequência, os professores não mais encontram uma rede que dê sustentação simbólica ao seu exercício profissional, o que promove mudanças na própria relação do jovem com o saber. Vejamos.

Ao escrever Uma lembrança de infância de Leonardo da Vinci, Freud (1911/2006b) traz elementos para pensarmos a origem do desejo de saber ao afirmar que a investigação científica somente é possível a partir da curiosidade da criança sobre a sexualidade. A busca pelo saber é, portanto, uma posição que o jovem assume como substituição à falta de saber sobre o sexo (Viola \& Vorcaro, 2013), que vai se manifestar, no adolescente, como uma urgência articulada à necessidade de encontrar um sentido àquilo que se apresenta como mais enigmático: o desejo do Outro. Se transpusermos tal elaboração para o contexto escolar, chegaremos à conclusão de que é preciso que o professor, enquanto suporte imaginário do Outro, se apresente em sua condição de sujeito desejante, para que, em seus alunos, possa emergir um desejo de saber.

Aqui, vale o esclarecimento de que o desejo de saber a que nos referimos não consiste numa tentativa de acúmulo de conhecimentos científicos, mas é justamente aquilo que possibilita a sua construção: o não-saber, o próprio vazio de sentidos causa do desejo do sujeito que aprende.

Assim, retomando o real sentido da transmissão em Freud, temos que ela não se dá no nível do conhecimento, mas no do desejo. Isso significa que não há um continuum pelo qual o conteúdo passa de forma integral do mestre ao aluno, mas uma descontinuidade, em que o mais importante não é propriamente a matéria transmitida, mas o ato da transmissão em si. Quando um professor, em seu ato educativo, se dirige a um aluno, uma dinâmica relacional entre os sujeitos é posta em cena. Desse modo, o conteúdo que se tenta transmitir por meio do ensino acaba se transformando nessa viagem de vai-e-vem, fundando aí um saber singular, somente possível pela via do desejo.

Trazendo para a questão que aqui nos interessa, se o desejo de saber só pode emergir pela transmissão na relação mestrealuno, mas, como apontado por Arendt (2007) e confirmado por autores contemporâneos (Duarte, 2001; Voltolini, 2012), o professor vem perdendo o seu lugar de autoridade - já que é mais valorizado que o aluno aprenda a aprender, ou seja, que o faça sozinho -, não é de se espantar que estejamos presenciando um declínio do sentido do conhecimento, conforme já apontado anteriormente.

Diante disso, os jovens, amparados pelas infindáveis possibilidades de acesso à informação, ao se depararem com o não-saber, frequentemente reagem não mais com o espírito do desafio de outrora, mas com a paralização provocada pela vertigem do abismo diante do vazio do saber (Lima \& Lima, 2011), já que não mais encontram suportes imaginários e simbólicos que sustentem a emergência de um desejo de saber. Traduzida pela via da inibição, a falta de sentido do conhecimento, para a juventude, pode desencadear um fracasso com todas as suas consequências, entre elas: a depressão, o sentimento de exclusão, a entrada nas drogas, a adesão a condutas delinquentes e, até mesmo, o suicídio.

Com relação a este último, Freud já o discutia como uma séria preocupação concernente aos casos de melancolia. Em seu texto Luto e melancolia (Freud, 1917/2006d), afirma que o que lhe confere um caráter enigmático é o fato de o processo melancólico implicar numa perda substancial da libido narcísica constituidora do próprio $\underline{\mathrm{Eu}}$, ou seja, é a instância mesma do $E u$ que sofre um profundo desinvestimento libidinal. Nesse sentido, levando em consideração o cenário descrito, se tomarmos a melancolização como um sintoma escolar, cabe o questionamento sobre o que vem produzindo, em nossos jovens, esse grave desinvestimento libidinal no próprio $E u$, bem como sobre qual seria o papel da escola nessa problemática.

Em Contribuições para uma discussão acerca do suicídio, Freud (1910/2006a) faz uma breve reflexão sobre a responsabilidade da escola nos atos cometidos por jovens contra a própria vida, no qual afirma que "uma escola secundária deve conseguir mais do que não impelir seus alunos ao suicídio. Ela deve lhes dar o desejo de viver" (p. 243).

Entender a relação entre a busca de sentidos (desejo de saber) como modo de sustentação da própria vida (desejo de viver) e a dificuldade humana de acessá-los é, aqui, muito importante. Na atualidade, a oferta de um espaço propício à produção de sentidos e, consequentemente, à transmissão de um desejo de viver na relação entre as gerações, incluindo a dos 
professores com seus alunos, parece vacilar. Numa época em que o acesso à informação é imediato, ilimitado e desenfreado, aquilo que é da ordem da experiência mesma do professor parece quase irrelevante.

A esse respeito, Benjamin (1985a) já observava a pobreza de experiências que caracteriza o mundo moderno, afirmando que, a cada dia, recebemos notícias de todo o mundo e, no entanto, quase nada nos acontece, porque tudo já chega pleno de explicações, não abrindo espaço à inserção do sujeito no campo desejante. Acrescenta: "uma nova forma de miséria surgiu com o monstruoso desenvolvimento da técnica sobrepondo-se ao homem" (Benjamin, 1985a, p.115).

Se retomarmos a discussão sobre a entrada de uma lógica neoliberal no campo da educação a partir de um viés psicanalítico, chegaremos a algumas considerações importantes acerca da aliança que vemos surgir entre o discurso da universidade e o do capitalista em detrimento do discurso do mestre que, tradicionalmente, sustentava a possibilidade de uma transmissão no contexto escolar (Lacan, 1972). Tal aliança designa um modo particular de relação do sujeito com o objeto, modo em que, segundo Voltolini (2012):

o objeto, agora coisificado por sua produção em série, empirizado pelo discurso científico, desconectado de seu fundo de ausência, tal como destacou a psicanálise com os conceitos de pulsão e de desejo, vem determinar, artificialmente, um 'sujeito em série', votado para o consumo. A hiperinflação do objeto, empreendida pelo capitalismo, visa estabelecer entre o sujeito e o objeto uma complementaridade sem arestas, o objeto sob medida na linguagem mercadológica, a existência da relação sexual, nos termos lacanianos, o paraíso nos termos bíblicos. (p. 111)

É verdade, esclarece Voltolini (2012), que, atravessados pelo discurso capitalista, os conhecimentos continuam sendo veiculados, mas não mais por intermédio de uma via pulsional. Se o conhecimento deixa de se conectar com o campo desejante e passa a configurar-se, também, como objeto a ser acumulado, isso, inevitavelmente, decairá em perda de sentido, transformando-se em mera informação (Benjamin, 1985b) e inviabilizando a real emergência de um desejo de saber.

Rahme e Mrech (2011) chamam a atenção para o fato de que esses objetos não se limitam, necessariamente, a bens materiais, mas também assumem a faceta de objetos que oferecem indicações de como ser melhor, como alcançar o sucesso profissional, como conseguir a segurança financeira; em suma, "como se dar bem na vida". Eles circulam no mercado, sustentando a ideia de que "nossa felicidade depende apenas de nossa competência pessoal" (Bauman, 2001, p. 87).

No entanto as desigualdades e a insegurança social são uma constante. A crise que assola a educação é demarcada pelos efeitos nocivos da perda de referências das novas gerações. A escola, então, encontra-se dividida entre um retorno nostálgico a um sentido que foi arruinado pela modernização e uma fuga diante do que a transformará numa máquina de formar competências para a economia, produzindo "diplomados" cujo valor social depende da oferta e da demanda (Laval, 2019).

O fato é que, com base no que foi apresentado, podemos concluir que o triunfo de um modelo educacional que se propõe a responder a demandas de eficácia e de inovação encontra seus limites na própria natureza do ato pedagógico, pois

não há ação educativa apenas com 'competências', 'técnicas', 'métodos”, se estes não tiverem como referencial uma dimensão fundadora da instituição que dê simbolicamente sustentação à troca, que seja o horizonte comum dos educadores e dos educandos. Sem essa mediação oferecida e sustentada pelo discurso da instituição, cairíamos no adestramento puro e simples, na brutal relação de força. (Laval, 2019, p. 297)

\section{Considerações Finais}

As tentativas de padronizar o ensino por meio de metodologias consideradas inovadoras, em nome de uma supostamente alcançável eficiência, parecem vir transformando as práticas educativas em meros "instrumentos de modelagem de competências", que servem aos interesses do mercado. Nesse sentido, a educação vem perdendo seu lugar enquanto espaço potencial de produção de subjetividade, o que traz efeitos nefastos à relação dos jovens com o saber e com a sua transmissão.

As demandas dirigidas à juventude, sendo veiculadas em termos de um êxito escolar, pois "é preciso estudar para ser alguém na vida", levam ao abismo da possibilidade, justamente, do ser ninguém, deflagrando a realidade de uma juventude desamparada. Sem referências nas quais possam sustentar-se, os jovens, cada vez de modo mais evidente, apresentam sintomas escolares que dão testemunho de uma perda do sentido do conhecimento, que não deixa de ser consequência, também, da entrada dos valores econômicos no campo educacional (Voltolini, 2012).

Assim, questionamo-nos: estaríamos vivendo uma nova crise na educação, diferente daquela discutida por Arendt (2007) na década de 1950? Em nossa análise, o que vivenciamos na atualidade não se trata de uma nova crise, pois o que já se anunciava desde o século passado enquanto problemática concernente ao contexto escolar parece permanecer como questão a 
ser solucionada nos dias atuais. $O$ fato é que as consequências diretas das razões, apontadas pela autora, da crise na educação, que já se anunciava no período pós-guerra, vêm ganhando novos contornos com o neoliberalismo penetrando o campo educacional.

A nova ideologia dominante parece negligenciar os objetivos culturais das escolas, bem como o seu papel antropológico de um modo geral, em nome de atender às demandas que o sistema econômico impõe a tais instituições (Laval, 2019). Se, antes, lhes cabia a função de promover uma formação intelectual e cidadã; hoje, resta-lhes o papel de treinar as habilidades de coletar, selecionar e tratar informações (Duarte, 2001) de forma autônoma, com o mínimo possível de interferência do outro, já que essa é a postura proativa que o mercado exige do trabalhador.

No entanto a crença de que a resolução dos problemas educacionais que presenciamos na contemporaneidade se encontra nessas ferramentas consideradas revolucionárias e inovadoras raramente se sustenta. A realidade do contexto escolar brasileiro tem-nos mostrado que a modernização das metodologias e a incorporação de novas tecnologias às salas de aula não são suficientes para resolver o fracasso escolar, nem a desmotivação dos alunos na busca pelo conhecimento.

Há, portanto, que se resgatar a função coletivizante do conhecimento. Não há como se alcançar uma verdadeira transmissão no contexto escolar sem que a sua principal condição de possibilidade, ou seja, o encontro do aluno com a alteridade e com a autoridade do professor, seja levada em consideração. Enquanto a juventude for treinada, mentorada, em prol de adquirir competências que, ilusoriamente, lhe garantiriam um lugar seguro no mercado de trabalho e a construção de sentidos compartilhados para o conhecimento for relegada à inutilidade, o resultado do triste caminho que vemos sendo trilhado pela educação em nosso país, provavelmente, permanecerá sendo o mesmo.

\section{Referências}

Acúrcio, M. R. B., \& Andrade, R C. (Org.). (2005). O empreendedorismo na escola. Porto Alegre/Belo Horizonte: Artmed/ Rede Pitágoras.

Adorno, T. (2003). Educação e emancipação. São Paulo: Paz e Terra.

Arendt, H. (2007). Entre o passado e o futuro. São Paulo: Editora Perspectiva.

Bandeira, B. S., \& Oliveira, A. R. (2012). Formação Cultural e semiformação: Contribuições de Theodor Adorno para pensar a educação hoje. Educação, 35(2), 225-232. Link

Bauman, Z. (2001). Modernidade líquida. Rio de Janeiro: Jorge Zahar Editor.

Benjamin, W. (1985a). O narrador. Considerações sobre a obra de Nikolai Leskov. In W. Benjamin, Magia e técnica, arte e política: Ensaios sobre literatura e história da cultura (Vol. 1, pp. 165-196). São Paulo: Brasiliense. (Série Obras Escolhidas).

Benjamin, W. (1985b). A obra de arte na era de sua reprodutibilidade técnica. In: W. Benjamin, Magia e técnica, arte e política: Ensaios sobre literatura e história da cultura (Vol. 1, pp. 197-221). São Paulo: Brasiliense. (Série Obras Escolhidas).

Costa, S. S. G. (2009). Governamentalidade neoliberal, teoria do capital humano e empreendedorismo. Educação \& Realidade, 34(2), 171-186. Link

Delors, J. (1998). Educação: Um tesouro a descobrir. São Paulo: Cortez.

Dolabela, F. (1999). Oficina do empreendedor: A metodologia de ensino que ajuda a transformar conhecimento em riqueza. São Paulo: Ed. de Cultura.

Duarte, N. (2001). As pedagogias do aprender a aprender e algumas ilusões da assim chamada sociedade do conhecimento. Revista Brasileira de Educação, 18(3), 35-41. Link

Fadel, C., Biliak, M., \& Trilling, B. (2016). Educação em quatro dimensões: As competências que os estudantes precisam ter para atingir sucesso. São Paulo: Instituto Ayrton Sena. 
Foucault, M. (2008). Nascimento da biopolítica. São Paulo: Martins Fontes.

Freud, S. (2006a). Contribuições para uma discussão acerca do suicídio. In: J. Strachey (Ed.), Edição Standard Brasileira das Obras Psicológicas Completas de Sigmund Freud (Vol. 11, pp. 140-144). Rio de Janeiro: Imago. (Originalmente publicado em 1910)

Freud, S. (2006b). Uma lembrança de infância de Leonardo da Vinci. In J. Strachey (Ed.), Edição Standard Brasileira das Obras Psicológicas Completas de Sigmund Freud (Vol. 11, pp. 36-82). Rio de Janeiro: Imago. (Originalmente publicado em 1911)

Freud, S. (2006c). Algumas reflexões sobre a psicologia do escolar. In J. Strachey (Ed.), Edição Standard Brasileira das Obras Psicológicas Completas de Sigmund Freud (Vol. 13, pp. 161-163). Rio de Janeiro: Imago. (Originalmente publicado em 1914)

Freud, S. (2006d). Luto e melancolia. In J. Strachey (Ed.), Edição Standard Brasileira das Obras Psicológicas Completas de Sigmund Freud (Vol. 14, pp. 139-153). Rio de Janeiro: Imago. (Originalmente publicado em 1917)

Goldberg, L. R. (1990). An alternative "description of personality": The Big-Five factor structure. Journal of Personality and Social Psychology, 59(6), 1216-1229. Link

Gutierra, B. C. C. (2002). O mestre (im)possível de adolescentes - uma especial posição subjetiva na transmissão. Estilos da Clínica, 7(12), 36-47. Link

Jaeger, W. (2003). Paidéia: A formação do homem grego. São Paulo: Martins Fontes.

Kupfer, M. C. M. (2000). Educação para o futuro: Psicanálise e educação. São Paulo: Escuta.

Lacan, J. (1972). Du discours psychanalytique. In J. Lacan, Lacan en Italie (pp. 32-54). Paris: Seuil.

Laval, C. (2019). A escola não é uma empresa: O neoliberalismo em ataque ao ensino público. São Paulo: Boitempo.

Lei $n^{\circ}$ 9.394, de 20 de dezembro de 1996. Estabelece as diretrizes e bases da Educação Nacional. Link

Lei $n^{\circ} 12.796$, de 04 de abril de 2013. Altera a Lei $n^{\circ} 9.394$, de 20 de dezembro de 1996. Link

Lima, M. S. A., \& Lima, M. C. P. (2011). Dos discursos freudianos sobre a educação: considerações acerca da inibição intelectual. Psico, 42(2), 212-219. Link

López-Ruiz, O. (2007). Os executivos das transnacionais e o espírito do capitalismo: Capital humano e empreendedorismo como valores sociais. Rio de Janeiro: Azougue Editorial.

Ministério da Educação [MEC]. (2000). Referenciais Curriculares para a Educação Profissional Técnica. Brasília, DF: Brasil. Link

Ministério da Educação [MEC]. (2013). Diretrizes curriculares nacionais da Educação Básica. Brasília, DF: Brasil. Link

Ministério da Educação [MEC]. (2017). Indicadores de fluxo escolar da educação básica. Brasília, DF: Brasil. Link

Nóvoa, A. (1999). Profissão professor. Porto: Porto Editora.

Oliveira, D. P., Lima, M. C. P., \& Colares, C. C. (2019). O desejo de viver e a transmissão do saber: Perspectivas psicanalítica e filosófica. Cadernos de Psicanálise, 41(41), 39-62. Link

Pereira, M. R. (2013). Os profissionais do impossível. Educação \& Realidade, 38(2), 485-499. Link 
Perrenoud, P. (1999). Construir as competências desde a escola. Porto Alegre: Artes Médicas.

Rahme, M., \& Mrech, L. M. (2011). Proliferação de objetos e empuxo ao gozo: Impactos do discurso capitalista na educação. In Universidade de São Paulo (Org.), Anais do $8^{\circ}$ Colóquio LEPSI IP/FE-USP. São Paulo: USP. Link

Rassial, J-J. (2002). O que os adolescentes ensinam aos analistas. São Paulo: Instituto de Psicologia USP.

Resolução CNE/CEB N. 06/2012. Define Diretrizes Curriculares Nacionais para a Educação Profissional Técnica de Nível Médio. Link

Schultz, T. (1973). Capital humano: Investimentos em educação e pesquisa. Rio de Janeiro: Zahar.

Viola, D. T. D., \& Vorcaro, A. M. R. (2013). Latência, adolescência e saber. Estilos da Clínica, 18(3), 461-476. Link

Voltolini, R. (2012). O conhecimento e o discurso do capitalista: A despsicologização do cotidiano social. Estilos da Clínica, 17(1), 106-121. Link

\section{Como citar:}

Oliveira, I. A., Maia L. M., \& Lima, T. J. S. (2020). Neoliberalismo Escolar: A Educação de Jovens na Atualidade e seus Efeitos Subjetivos. Revista Subjetividades, 20(Esp 2. O Contemporâneo à Luz da Psicanálise), e10544. http://doi. org/10.5020/23590777.rs.v20iEsp2.e10544

\section{Endereço para correspondência}

Lorenna Pinheiro Rocha

E-mail: lorennapinheiro@hotmail.com

Maria Celina Peixoto Lima

E-mail: celina.lima@unifor.br

Clara Virgínia de Queiroz Pinheiro

E-mail: claravirginia@unifor.br 